\title{
Force Sensing Resistor and Evaluation of Technology for Wearable Body Pressure Sensing
}

\author{
Davide Giovanelli and Elisabetta Farella \\ Fondazione Bruno Kessler, Via Sommarive 18, 38123 Povo, Italy \\ Correspondence should be addressed to Davide Giovanelli; dgiovanelli@fbk.eu \\ Received 6 September 2015; Revised 13 January 2016; Accepted 17 January 2016 \\ Academic Editor: Alberto J. Palma
}

Copyright ( 2016 D. Giovanelli and E. Farella. This is an open access article distributed under the Creative Commons Attribution License, which permits unrestricted use, distribution, and reproduction in any medium, provided the original work is properly cited.

\begin{abstract}
Wearable technologies are gaining momentum and widespread diffusion. Thanks to devices such as activity trackers, in form of bracelets, watches, or anklets, the end-users are becoming more and more aware of their daily activity routine, posture, and training and can modify their motor-behavior. Activity trackers are prevalently based on inertial sensors such as accelerometers and gyroscopes. Loads we bear with us and the interface pressure they put on our body also affect posture. A contact interface pressure sensing wearable would be beneficial to complement inertial activity trackers. What is precluding force sensing resistors (FSR) to be the next best seller wearable? In this paper, we provide elements to answer this question. We build an FSR based on resistive material (Velostat) and printed conductive ink electrodes on polyethylene terephthalate (PET) substrate; we test its response to pressure in the range $0-2.7 \mathrm{kPa}$. We present a state-of-the-art review, filtered by the need to identify technologies adequate for wearables. We conclude that the repeatability is the major issue yet unsolved.
\end{abstract}

\section{Introduction}

Modern electronics has reached a level of integration that has made it possible to include computational capabilities into everyday objects. Moreover, garments can exploit the potential of digital electronics, embedding sensor and actuators. Both the industry and scientific research are pushing on this kind of devices, commonly called wearables [1].

Wearables are generally employed to collect information about the user and data is usually related to some particular activity or some physiological parameters. Wearability is one of the key points involved in the design of such kind of devices; in fact the primary goal is to perform the measure in an unobtrusive but reliable way. Furthermore, the accuracy and reliability of measurement play an important role, particularly in health and professional sport applications, where wearables aim at substituting or at least act as outdoor companion of laboratory and hospital high-quality appliances.

Activity trackers, embedding inertial sensing, are one of the most popular kinds of wearables, leveraging on the need of the consumer to keep healthy behaviors, stay active, and care for her/his fitness. However, sometimes their accuracy is controversial. Another important yet overlooked aspect related to daily life comfort and health is the impact on posture and comfort of what we bear with us every day such as bags, backpack [2], or sport equipment. Even what we wear such as shoes [3-6] or professional vests for bearing objects, like those used by the military [7] or by professionals, can affect comfort and posture $[8,9]$.

For example, a challenging task is the monitoring of pressure exerted by a backpack on the shoulders and on the back of the user $[8,10]$, which is complicated by the uncontrollability of the strap-shoulder interface and by user movements [11]. Several research works address this issue to extract meaningful information having an impact on ergonomy [2] or user posture $[9,12]$.

A field where interface pressure sensors are applied with similar constraints as in wearables is robotics. In this scenario, touch sensors are employed to close the feedback loop needed to accurately control the grasping force, giving to a robot (or to a prostheses) the possibility of handling objects [1315] with a controlled force. However, a robotic hand typically 
offers at least one rigid surface. Instead, the human body surface is soft and skin and tissues have complex and variable mechanical properties.

In all these examples, the contact interface pressure exerted on the body by the object under investigation is, among others, a key physical quantity to take into account. Therefore we will not be surprised if the next wearable coming in the market would be a "comfort tracker" based on interface pressure; but why is it not happening? Application of contact interface pressure sensors to commercial products is restricted to gait analysis [16] and, to the best of the authors' knowledge, no other commercial device based on contact interface pressure sensors has been already presented on the market. Some products exist but they are addressed to professionals, researchers, or doctors [17-19].

In this paper, we report our experience in exploring the design space of contact interface pressure sensors that are adequate to be part of a wearable; for this reason we focus on the sensing technologies that are compliant with the integration inside garments or other kinds of clothing (i.e., shoes, backpacks). We concentrate on the sensor and its conditioning electronics since the other components (i.e., GPIO interfaces, microcontroller, and power supply) are shared with the majority of wearable devices. An analysis of the literature on force sensors is performed with focus on transducers that can be used for wearables. Sensor structures, electronics, and processing algorithms are discussed. A low cost flexible force sensor, made with Velostat and conductive ink electrodes printed on PET substrate, is realized and tested. Experiments are executed in laboratory, with test procedures that are targeted to investigate their performance. Considering five tests, executed on different days, the signals acquired in the same conditions show that the amplitude can reach twice the value of a previous measurement. We conclude that the poor performance, in particular the repeatability of this sensing technology, is one of the main reasons of its relatively low diffusion for commercial devices.

The paper starts with an overview of force sensing technologies together with a brief explanation of the physical phenomena that are behind these sensors (Section 2). Section 3 is focused on technologies that comply with the need of wearables; in particular materials and sensor structures are described. Error compensation techniques are described in Section 4 and to complete the work some tests on a custom interface pressure sensor are reported and discussed (Sections 5, 6, 7, and 8).

In the following, the terms pressure, interface pressure, and contact pressure are used as synonyms since the measurement of other types of pressure such as absolute atmosphere pressure is not the scope of this paper.

\section{Force Sensing Overview}

All applications mentioned in the previous section rely on force sensors; on the market and in scientific literature there are several transducers used to convert force into an electric quantity [20,21]; each of these has its own advantages and disadvantages. In the following, we will use the terms force and pressure as synonyms, considering that force is pressure over an area, assuming that the area is known.

It is not easy to catalog the whole set of force sensors since many forms and many physical effects are involved. Here the subdivision is made using the physical quantity exploited to quantify the force. In this context we find sensors involving a variation of an electrical property (resistance, capacitance, or more generally impedance), sensors generating a charge displacement (piezoelectric), and others that use different physical quantities (light, magnetic field) to measure the displacement variation of a known material [20-22]; also out-ofthe-box barometric MEMS (Micro Electromechanical Systems) can be used to measure interface pressure [21, 23].

Since the electrical resistance of a conductor is function of its mechanical dimensions, if it is deformed a precision ohmmeter can detect the difference in electrical resistivity. This principle is used by strain gauges to convert a strain into a resistance variation. Moreover, within some limits, the strain of a material has a well defined relationship with force; therefore through the measure of the deformation obtained from the strain gauge, it is possible to calculate the actual force.

Since strain gauges are sensitive to deformation in all directions, gauges are often connected together in a Wheatstone bridge circuit; this helps to amplify the small resistance changes and it leads to a differential configuration, where components can be summed or canceled depending on their sign. As an example, shear forces and temperature effects can be canceled as presented in [24]. Load cells often use this technology.

A promising type of pressure sensors for wearable applications is force sensing resistors (sometimes called piezoresistive sensors). They are resistive sensors, such as strain gauges, but they rely on different working principles. In fact strain gauges are based on the variation of length and width of the conductor, while force sensing resistor is based on the variation of conductivity of the sensor itself. There are of course also mechanical deformations but they produce different effects. A clear demonstration of this is that a strain gauge produces a variation of resistance that unlikely exceeds $0.5 \%$. Instead a commercial force sensing resistor has a range that is typically wider than one order of magnitude $[18,25]$. This category of sensor will be analyzed closely later.

Piezoelectric force sensors are based on the piezoelectric effect of some materials, which generate an electric charge when stressed. To extract the charge information a sophisticated electronic is needed since parasitic effects tend to recombine the charge making the material shortly neutral. This implies that these transducers can hardly be used to measure static or slow varying forces; this can be solved by combining information coming from other kinds of pressure sensors ([5]). Moreover, a protection has to be provided to the electronics since if the sensor is actuated with a big and impulsive force high voltages, up to thousands of volts, can be generated.

Capacitive force sensors are usually a parallel-plate capacitor, which changes its capacitance in function of the applied force. This is due to the dielectric that, in this case, is an elastomer or another sort of squeezable material that gets 
thinner when subject to pressure $[19,26]$. Even with these sensors the conditioning circuit is complex and subject to noise due to connecting cables.

Other types of force sensors exploit different effects: some are based on light [22] and others on magnetic sensors [21]. They mainly use the measurement of the displacement that the force generates on an elastomer (i.e., by knowing the displacement of a spring it is possible to calculate the force that is acting on it through the elasticity coefficient).

Finally, barometric MEMS can be used to sense an interface pressure if they are drowned in some soft or liquid material such as silicone. They actually sense the pressure of silicone that can be related to the force acting on it $[9,21,23]$. All these sensors rely on the mechanical characteristics of the constructing material.

Not all the previously mentioned types of force sensor are appropriate for wearable applications; in fact most of them have been developed for mechanic applications where the materials that are involved are usually steel, aluminum, or other stiff materials.

If the interface pressure measurement has to be done on the body surface, requirements are different from those needed for mechanics. First of all, as already mentioned, the presence of a bulky and hard sensor, even if small, can be a problem since it causes areas of higher contact pressure. This of course falsifies the measurement; moreover it could reduce acceptability and usage comfort.

Since for many applications a pressure map is more useful than a single measurement the unit cost of each sensor has to be low and the fabrication process has to be scalable.

With these requirements, it is clear that sensors in form of load cells (that can be based on strain gauges or piezoelectric effect) are not appropriate. Even though on the market there are some load cells that are rather thin, down to $2.5 \mathrm{~mm}$ [27], and can be used in some wearable application, their rigidity and cost remain a problem.

In contrast, strain gauges can be built on flexible substrates, and for this reason they can be adapted and used for wearables.

Piezoelectric sensors can be found in the form of load cells, with the same cons described in a previous paragraph, or in the form of flexible thin film, made of a piezoelectric polymer, for example, polyvinylidene fluoride (PVDF) [28] or piezoelectric zinc oxide ( $\mathrm{ZnO})$ [29]. These flexible materials can be used to sense force or pressure but it is sensitive to many factors (i.e., bending, temperature) [28]; thus difficult modeling is needed to compensate parasitic effects. Moreover, it remains a piezoelectric sensor and thus it cannot be used to measure static forces.

Capacitive sensors can be built using flexible materials making them a suitable choice for body pressure measurements but the parasitic capacitance of sensor connections and the complexity of needed electronics limit their usage and integration inside garments, especially if the cost is a constraint.

Piezoresistive/force sensing resistors instead have the advantages that can be fabricated using flexible materials, but also they are very robust against noise and the conditioning electronics is simple; that is, in many cases only a bias resistor is used [30]. Moreover, the unit costs are relatively low for commercial ones and very low if they are custom-made as the one used in our experiments. However, performance of these sensors is known to be quite poor; as an example in [31] a repeatability error up to $15 \%$ is found within an experiment performed with a controlled load machine. Therefore an evaluation is needed to verify if they are suitable for a given application.

Other types of sensors mentioned earlier are not evaluated here since they are custom prototypes, not available in market.

\section{Flexible Resistive Force Sensors}

From the categories exposed in previous sections, this study is focused on resistive sensors because they are widely used; they involve low cost electronics and therefore suitable for wearables, even for those targeting the consumer market.

Since there are some different physical effects that drive the working principles of these sensors, we adopt a classification similar to [32], where four physical phenomena are described:

(i) Strain Gauge: they rely on the change of resistance of a deformed conductor.

(ii) Quantum Tunneling: it exploits the tunnel effect that drives the conduction in a composite where conductive fillers are dispersed inside a polymeric matrix. When a pressure is applied the distance between conductive particles inside the composite changes, varying the overall material conductivity.

(iii) Percolation: in this case it takes the advantages of undergoing a threshold between an insulating state and a conductive one [33]. The threshold depends on the amount of conductive filler dispersed in the matrix, and of course this is influenced by the applied pressure since the deformation modifies contacts between particles creating/destroying direct conductive path inside the matrix.

(iv) Piezoresistivity: this is the generic term used to describe the propriety of a material to change its conductivity with respect to the applied pressure.

More than one aforementioned effect is present on the same sensor category but one dominates over the others $[32,34]$.

The remainder of this paper will be focused on sensors exploiting percolation effect, since they can be made with extremely low cost and easy available materials. Moreover from our literature analysis, there is no clear advantage in using quantum tunneling sensors. Strain gauges have better general performance, but there is no known way to easily use them as interface pressure sensor, in particular if they must be applied on a wearable device where the Wheatstone bridge configuration cannot be effectively exploited.

3.1. Sensor Structures. When a sensor is built to exploit percolation (but similar procedure is used for quantum tunneling based sensors) the resistance of a composite material is measured through the use of some electrodes that are in 


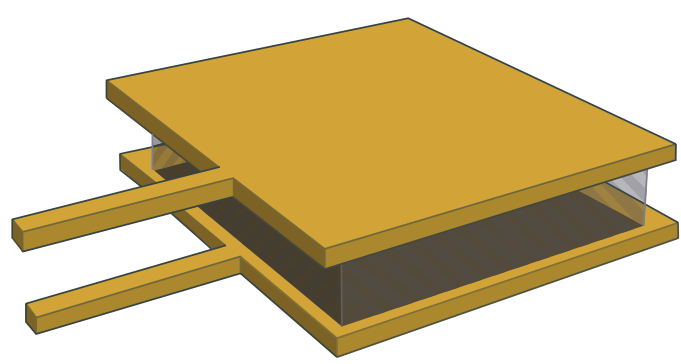

(a)

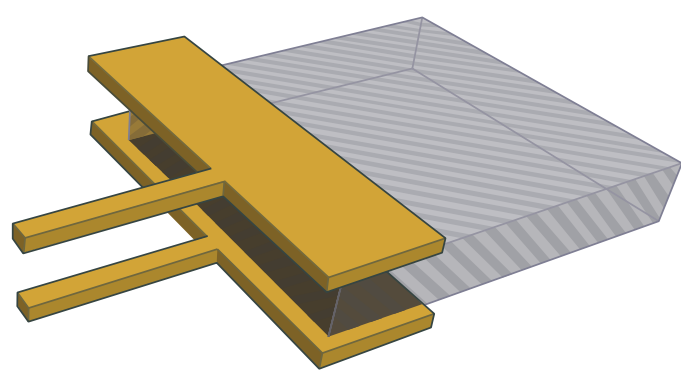

(c)

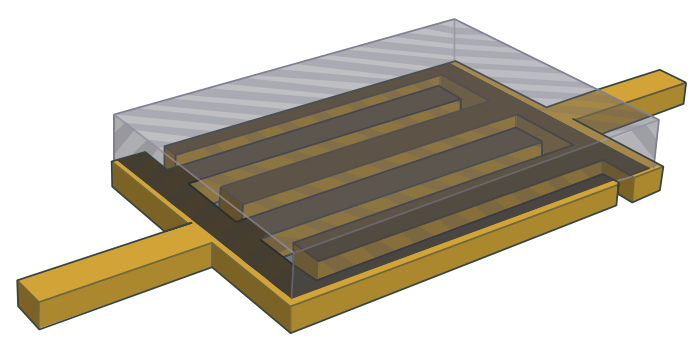

(b)

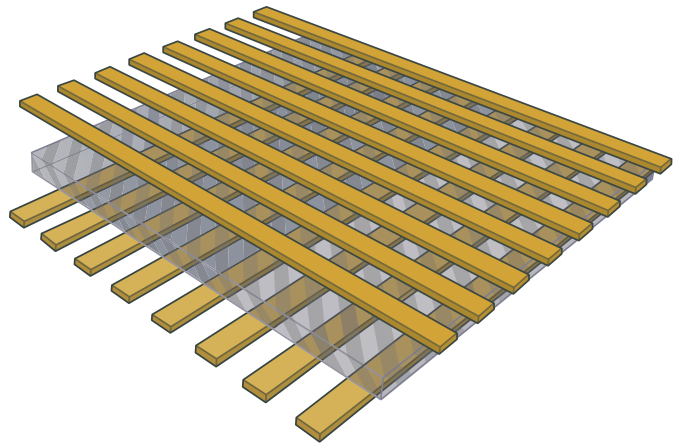

(d)

FIGURE 1: Common sensor structures, copper or conductive lines/electrodes are in yellow; polymeric composite is in transparent gray: (a) single point sensor sandwich structure, (b) single point sensor interdigital structure, (c) single point sensor fringe electrode structure, and (d) sensor matrix.

contact with the polymeric composite. Those electrodes can be embedded inside the material during fabrication [34,35], glued to material $[36,37]$, or in contact with it [37-39]. In the first two cases surface resistance between electrodes and composite is constant; otherwise if the electrodes are not glued, surface resistance variation can have big impact on the overall effect [31,37].

Contact pressure sensors can be divided into two main categories, that is, single point sensors and matrices. Examples of both can be found in commercial products and in research prototypes.

Single point implementations are sensors able to sense pressure or force in a small area; therefore they have a single output and are of small size and low cost. A popular structure is the sandwich-like one; it is built with the two electrodes on both sides of the composite [39] (Figure 1(a)). Another solution that can help to save space and costs is to place both electrodes side by side [37] (or with an interdigital structure [14]) on the same side of sensing material (Figure 1(b)). There are also some works that place electrodes away from the sensing area $[34,40]$ (Figure 1(c)); this increases flexibility, but on the other side the sensibility is reduced due to the fixed resistance contribution that cannot be separated from the variable part. Sensors matrices are more useful when a pressure map is needed instead of the information that relates only to a single point $[30,38,41]$. The most simple structure is based on horizontal and vertical electrodes that are placed on both sides of sensitive polymeric material (Figure 1(d)). The matrix is read by activating a horizontal line and reading resistance of each vertical line; then that horizontal line is driven to neutral voltage and the subsequent line is activated. In this way all the matrix is scanned.

3.2. Resistive Composite. The sensing part of percolation based pressure sensors is the resistive material that connects the electrodes (Figure 1). This resistive material is basically a mixture of conductive particles and an insulating material that acts as suspension matrix.

Researchers often produce their own composite material with desired electrical/mechanical proprieties. A lot of variants exist $[32,34,37,38,40,42]$ but in the majority of cases they consist of a polymer such as polydimethylsiloxane (PDMS) $[32,34,38,40,42]$ that is a silicone rubber or ethyl vinyl acetate (EVA) $[37,43]$ mixed with conductive particles. The weak point of these bespoke composites is that they are custom-made; therefore they are difficult to reproduce and/or to fabricate in scale if the final objective is to use them in today's commercial wearables.

Some manufacturer made resistive composite for other purposes such as antistatic protection or shielding and, in some cases (such as Velostat/Linqstat produced by $3 \mathrm{M}$ ), they are suitable for making force sensing resistor $[31,39,44]$. Since these materials are industrially produced they are easily available and of low cost; this is the main reason why we selected Velostat for our sensor.

Some specialized sensor manufacturers use conductive inks $[18,25]$ to ease the mass production; unfortunately their processes are not extensively documented since they are covered by patents.

In general, the mix of a polymer with conductive particles such as carbon black $[36,38]$, graphene, or carbon nanotubes 
[34, 40,42, 45] generates a resistive composite material. Changing particles size, shape, and concentration leads to different dominating effects (negative or positive pressure coefficient of resistance). Carbon nanotubes, which have elongated shape, make the resistance of composite increase with pressure $[42,45]$; instead, carbon black particles that have a more spherical-like shape tend to make a negative pressure coefficient of resistance [32]. Some results suggest that the sign of the dominating effect is also dependent on the electrodes [38].

As already said, more conduction mechanisms can take place inside the same composite [32,38]. As an example, in carbon nanotubes composite a positive coefficient of resistance is observed for percolation mechanism but at the same time quantum tunneling conduction, which has opposite trend, occurs.

\section{Common Problems and Proposed Solutions}

The performance of a generic sensor is usually evaluated in terms of the following:

(i) Linearity: how linear the output is with respect to input solicitation.

(ii) Drift/stability: how the output varies if a constant (long duration) solicitation is applied.

(iii) Hysteresis: how much a loading unloading cycle can affect the output at a given solicitation.

(iv) Homogeneity: how similar the responses of two specimens of the same sensor are.

(v) Repeatability: how the response varies if it undergoes the same solicitation in the same test conditions.

For polymer based sensors almost all these figures of merit are poor [14, 31, 38, 46-48], but some effort has been done to reduce or compensate errors. It is important to point out that a technique that improves sensor performance only on a test bench with a specific stimulus $[38,44,49]$ is useless if the same technique cannot be applied on real signals acquired "on field."

The linearity problem is faced mainly with the use of proper conditioning circuit. If only qualitative information is requested, the high nonlinearity of resistance response can be discarded and a simple bias resistor can be used [30,50]. In fact, due to their transfer function, these sensors can be used to make a logarithmic-like response, where at low pressure the sensitivity is high but as the pressure increases it is reduced leading to a sort of dynamic range compression. A more linear response is obtained using a transimpedance amplifier (Section 5.2) and if further improvements are requested a calibration based on a polynomial equation can be used [50,51].

Drift and stability are usually related to the relaxation/ creep of the resistive material subject to a stress [31, 38, 39]. A proposed solution for this is the modeling of the creep effect [52] with the aim of removing the unwanted effects by a system inversion $[38,39]$. With this approach the polymer is modeled as viscoelastic material that has a response with at least two contributions; one is almost instantaneous and the other is slower. A problem with this method is that the material shows a different time constant during loading and unloading. Some solutions have been proposed [38], but it is not clear if it is possible to apply this solution to arbitrary signals.

The hysteresis can be treated with complex mathematical models [53] or with a simpler algorithm that takes into account the moving integral of sensor's signal [51]. It must be noted that when the material is modeled as viscoelastic material the time constant of first-order model is quite long (using Velostat we calculate a time constant of 311 seconds). This slow response of material can be confused with hysteresis since a loading/unloading cycle inevitably takes some time; then the integral of applied stress within the test gives some contribution to the reading at the end of the cycle. For this reason hysteresis tests should be done carefully. A solution can be performing tests with long cycles; in this way the slow response of material is ended and results are consistent. Otherwise using short cycles it is possible to discard the material relaxation since its effect is negligible within short periods of time. As reference, we consider a short period when the duration is less than 0.01 times the time constant of the first-order system that best characterizes the sensor and long periods when the duration is longer than 5 time constants.

Homogeneity is a problem when calibration and other techniques exposed here cannot be performed on every used sensor [14, 31]. Characterization of every sensing point is complicated especially when working on sensor matrix since many points should be stimulated in a controlled way. For this a classical solution is the usage of pressurized chamber $[19,50]$.

Repeatability is one of the mayor issues of resistive pressure sensors and no clear explanation has been already found. With these sensors the same measurement, performed with the same conditions, can lead to different results [5456]; similar results are found with both commercial and custom sensors.

\section{System Description}

5.1. Sensor. The sensor we used during our tests was developed in the context of an industrial project with the aim to enhance a backpack with pressure sensors. Since the objective was the design of a commercial product the cost was the primary constraint. This excludes much of the previously mentioned force sensing technologies and the choice was to develop a custom sensor.

To decrease cost and simplify integration and especially the wirings, we choose the interdigital structure proposed in Figure 1(b), with dimensions $1.5 \mathrm{~cm} \times 3 \mathrm{~cm}$ (Figure 2(a)). After some preliminary experiments with materials not reported here, we chose Velostat because it is readily available and it is a standard technology, with an affordable price. Those are characteristics that well suit our initial aim: to develop a commercial low-end wearable gadget. Although we used an interdigital structure we were interested in monitoring a wide area; therefore we developed a matrix 


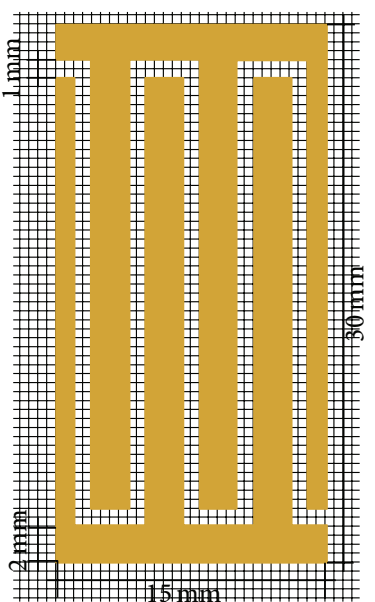

(a)

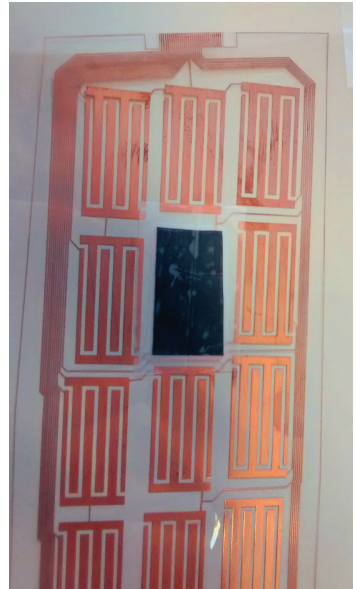

(b)

FIGURE 2: (a) Interdigital electrode structure used in our sensor: grid spacing is $0.5 \mathrm{~mm}$. (b) The actual sensor used for our experiments. Electrodes are printed with conductive ink on flexible PET substrate. Velostat, visible in the center of the figure, is trimmed and fixed with tape to avoid shifts.

(visible in Figure 2(b)) that uses only one layer for electrodes and interconnections, avoiding the typical matrix structure showed in Figure 1(d). The matrix has been printed (by an external company [57]) with conductive ink in a twostage patented process (InkJetFlex technology): first stage is printing the design using a catalytic ink; the second stage is the copper plating process. With this process sheet resistance of $30 \mathrm{~m} \Omega$ /square is obtained. A successive antitarnish treatment with benzotriazole has been applied. The printing substrate is Stabilex SU320 (flexible PET), 125 microns thick. Experiments were done on a single matrix element (visible in Figure 2(a)). The Velostat foil was trimmed with the same dimensions of electrodes $(1.5 \mathrm{~cm} \times 3 \mathrm{~cm})$ and, to avoid shifts, it has been fixed to the PET substrate with normal tape.

The total sensor interconnections resistance is $R_{\mathrm{int}}=50 \Omega$ (measured with a Fluke 175 multimeter) and it is summed to sensor resistance since it is in series. To solve this we applied a correction on all acquired data prior to any analysis that cancel the effect of $R_{\mathrm{int}}$.

5.2. Conditioning Electronics. As conditioning circuit we used a transimpedance amplifier, which is a current to voltage converter. This circuit is especially suitable when a sensor matrix has to be scanned [38, 43, 45]. Furthermore, sensor conductance is easier to handle than resistance being directly proportional to pressure $[32,39]$; in fact this circuit (Figure 3(a)) is advised by commercial sensor producers [18, 25].

Since our system needs to be portable and battery powered we had the restriction of using a single side supply at $3.3 \mathrm{~V}$. To overcome this constraint without reducing dynamic range some modifications are made to the basic circuit configuration. Our final circuit is shown in Figure 3(b) and it has the benefits that the voltage across the sensor can be maximized (near to $V_{c c}$ if the operational amplifier supports
$V^{+}$and $V^{-}$to be close to $V_{c c}$ ), making it possible to reduce feedback resistor (for a given gain) and then reduce noise due to current generated by magnetic flux concatenated in connections path. Moreover the output swing is increased by setting the output offset voltage with $R_{B}$.

With the proposed circuit, the sensor conductance can be computed with this formula:

$$
G_{s}=\frac{1}{R_{s}}=\frac{2}{R_{f} V_{\mathrm{cc}}}\left[V_{\text {out }}-\frac{V_{\mathrm{cc}}}{2}\left(1-\frac{R_{f}}{R_{B}}\right)\right],
$$

where symbols refer to Figure 3(b) (low pass filter response, due to feedback network, has been discarded).

\section{Test}

6.1. Experimental Setup. The described system has been positioned on a bench and acquisition is done by a National Instruments USB-6210, which has 16-bit analog to digital convert (ADC). Acquired data is stored on a PC and is analyzed off-line with Matlab. The pressure solicitation is done with reference weights made of steel and a $7 \mathrm{~mm}$ thick layer of EVA has been used to homogenize pressure between weights and Velostat. The area of pressure is determined by the weights size, that is, $5.6 \mathrm{~cm} \times 7.5 \mathrm{~cm}$. The same conditions are maintained to the best of our possibilities during the whole experiment. The use of weights is prone to inaccuracies since it is a manual process; however it well reproduces reallife conditions where the environment is not controlled. For this reason, we state that if the sensor has problems with weights that lead, after all, to a rather controlled condition it will have much more problems working on a wearable device where bending, shaking, shear force, and other artifacts occur. 


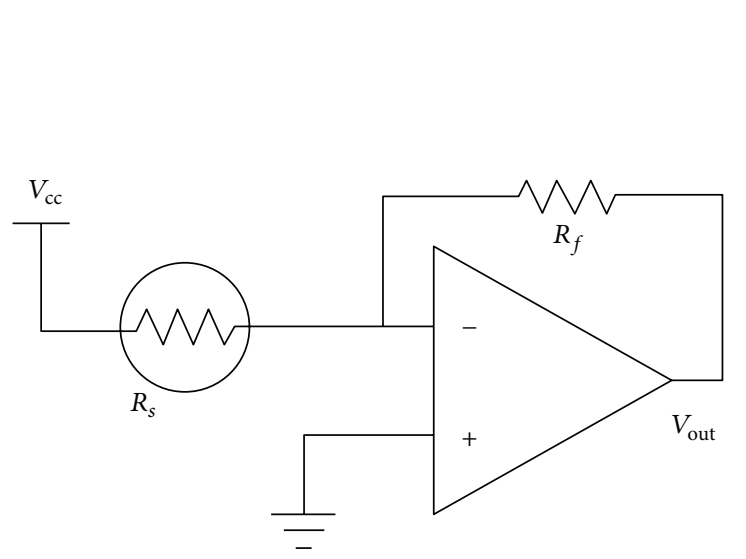

(a)

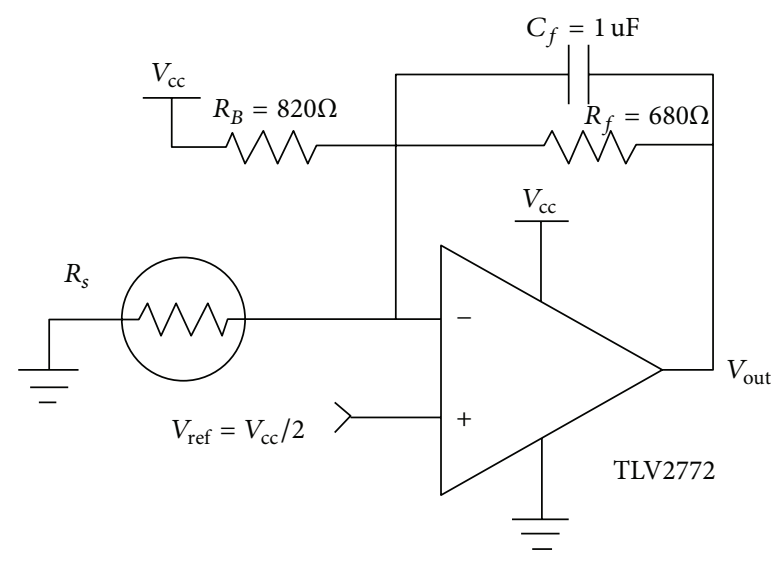

(b)

FIgURE 3: (a) Simple transimpedance amplifier. (b) The same circuit adapted to overcome constraints imposed by the system. The resistor inside circle $\left(R_{s}\right)$ represents the pressure sensor under test.

\subsection{Performed Tests and Results}

6.2.1. Viscoelastic Modeling. The first test aimed at extracting parameters for a standard linear solid (or viscoelastic) model similarly as done in $[38,39]$, with the purpose of correcting errors due to material's creep. The response of the used model has two components, one that is proportional to the stimulation and one that is slower and evolves exponentially, as a typical first-order system. The overall step response of such system given by

$$
S=A\left[k_{P}+k_{e}\left(1-e^{-\left(t-t_{0}\right) / \tau_{\text {response }}}\right)\right],
$$

where $S$ is the strain and it is measured in microstrain that is the deformation expressed in terms of parts per million. A is the amplitude of the input step; in our case it is a pressure. $k_{P}$ and $k_{e}$ are weighting coefficients of the proportional and exponential part of response. $\tau_{\text {response }}$ is the time constant of the model and $t_{0}$ is the step starting time.

For our model we consider a linear relationship between sensor conductance and exerted pressure [18, 25, 32, 39]; therefore considering (2) and the linearity of conditioning circuit with respect to sensor conductance we can write the expected $V_{\text {out }}$ trend as

$$
\begin{aligned}
V_{\text {out }} & =V_{O}+S K^{i} \\
& =V_{O}+A\left[k_{P}^{i}+k_{e}^{i}\left(1-e^{-\left(t-t_{0}\right) / \tau_{\text {response }}}\right)\right], \\
V_{O} & =V_{B}+V_{L},
\end{aligned}
$$

where the new coefficients $k_{P}^{i}=k_{P} K^{i}$ and $k_{e}^{i}=k_{e} K^{i}$ take into account a multiplying factor $\left(K^{i}\right)$ due to the circuit gain and sensor physical dimensions. $V_{O}$ is the offset which is composed by the electric bias $\left(V_{B}\right)$ and by an offset due to linearization $\left(V_{L}\right)$ of output voltage with respect to pressure. Since the relaxation time is different in loading/unloading we focus only on loading for the moment; furthermore in the analysis the offset value due to electronics biasing $V_{B}$ has been removed.

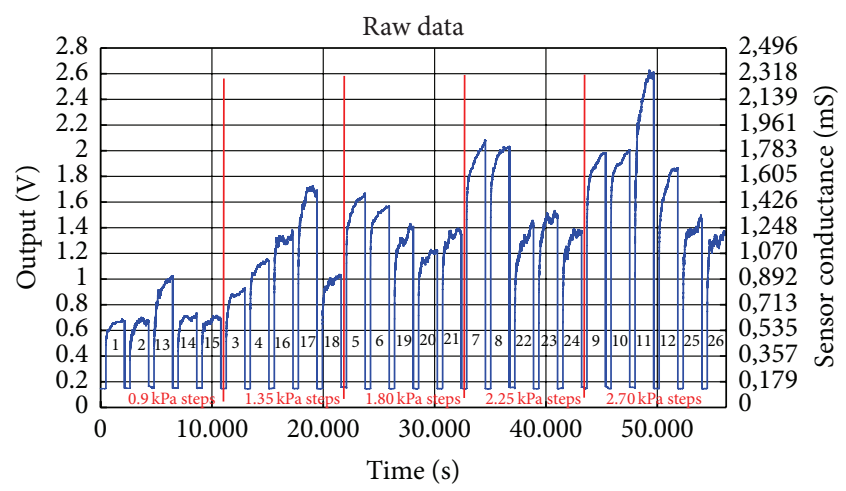

FIGURE 4: Raw output data from viscoelastic modeling tests (electronic bias $V_{B}$ has been compensated). Numbers inside steps are the actual ordering of performed trials (after the test has been performed, trials were truncated and reordered for clarity). The red values below the signal trace are the amplitude of steps generated by reference weight on an area of $5.6 \mathrm{~cm} \times 7.5 \mathrm{~cm}$. Multiply output voltage for $\left(V_{c c} / 2\right)\left(1-R_{f} / R_{B}\right)$ to convert it to sensor conductance.

Material showed quite long relaxation time ( $\tau_{\text {response }}$ in the order of 300 seconds); therefore each test followed this procedure: sensor output recording is started and data is acquired for 10 minutes without any load; the weight is applied on the sensor and output is recorded for 30 minutes; afterwards the weight is removed and the recording is stopped. A rest time of 20 minutes follows before another cycle starts. With this procedure the sensor is loaded for 30 minutes and unloaded for the following 30 minutes. Tests have lasted 5 nonconsecutive days that were distributed in 10 days.

We used five input pressures levels (marked in red in Figures 4 and 5(a)) and for each pressure the test has been repeated five times.

All the acquired data have been queued, $V_{B}=0.28 \mathrm{~V}$ offset has been removed, and results are showed in Figure 4. 


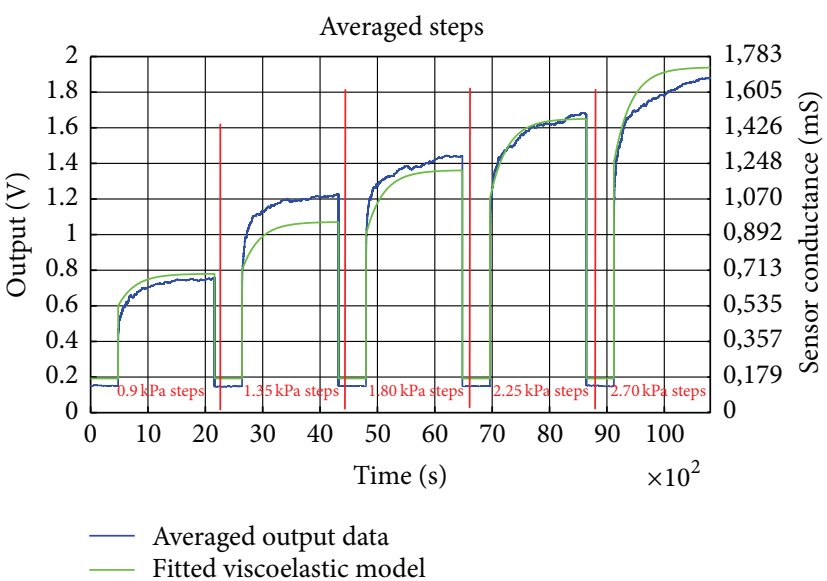

(a)

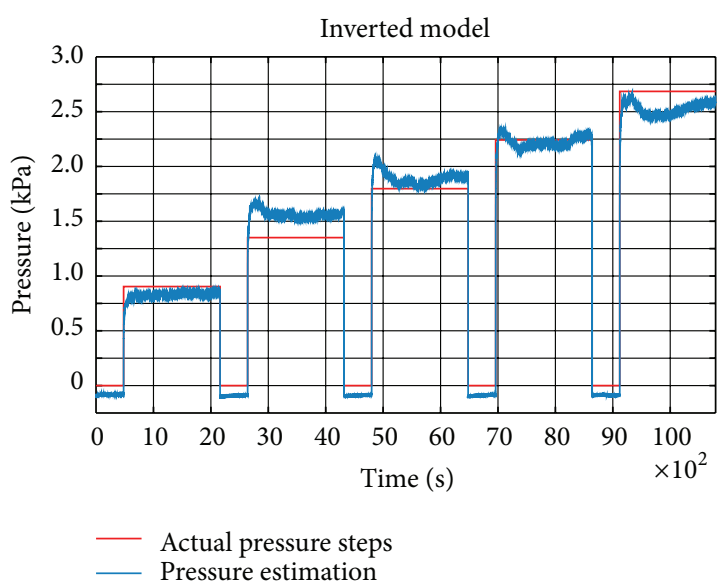

(b)

Figure 5: (a) Data obtained averaging the whole period (step). In blue is the obtained data after averaging the same pressures periods plotted in Figure 4. In green is the simulation of the viscoelastic model whose parameters are extracted through linear regression and as input the same signal imposed on the real sensor. Multiply output voltage for $\left(V_{\mathrm{cc}} / 2\right)\left(1-R_{f} / R_{B}\right)$ to convert it to sensor conductance. (b) Pressure estimation obtained using the inverse system and averaged sensor's data as system input.

With these results we state that on average the sensor behavior is monotonic but the repeatability of results is low since for the same pressure (i.e., with $2.70 \mathrm{kPa}$ ) up to a factor two of difference is observed between the lowest and the highest output value. To try solving this we have overlapped and averaged trials with the same input obtaining a mean trend for each pressure level; we called this procedure Period Averaging. Results from this processing are showed in Figure 5(a) (blue line); now the signal evolution is closer to the behavior of a first-order system whose parameters can be extracted using linear regression.

Referring to (3) the fitted model that we have calculated has these parameters:

$$
\begin{aligned}
k_{P}^{i} & =4.56 \times 10^{-4}[\mathrm{~V} / \mathrm{Pa}], \\
k_{e}^{i} & =1.97 \times 10^{-4}[\mathrm{~V} / \mathrm{Pa}], \\
\tau_{\text {response }} & =311[\mathrm{~s}], \\
V_{L} & =0.192 \mathrm{~V} .
\end{aligned}
$$

Multiplying $k_{P}^{i}$, $k_{e}^{i}$, and $V_{L}$ for $\left(V_{\mathrm{cc}} / 2\right)\left(1-R_{f} / R_{B}\right)$ gives the same parameters with conductance in place of volts. These new sets of parameters are specific for this sensor and independent of conditioning circuit.

Simulating the response of the system with these parameters is possible to view how the ideal viscoelastic model approaches the acquired data (Figure 5(a)). Furthermore it is possible to invert the system; the obtained one accepts acquired data as input and returns the estimated pressure (Figure 5(b)).

After processing, the mean rms error obtained within the test range is $9.4 \%$ with respect to the actual solicitation value.

It has to be remarked that these results have been obtained using the average of five test cycles; therefore this processing technique is suitable for periodic signals only; moreover the output has a delay equal, in this case, to five times the cycle duration. Moreover error is calculated using the same test set used to calculate system coefficients; then it is an underestimation.

6.2.2. Dynamic Response Modeling. This test aims at characterizing the sensor with respect to dynamic signals to whom the contribution of exponential in (3) is negligible. For this purpose a fixed pressure offset is exerted on the sensor with a weight that has been placed at least 2 hours before starting the test; this ensures that the material has reached the stability. The test consists in soliciting the sensor with a square wave with a period of 10 seconds and $50 \%$ duty cycle; each test lasted 10 minutes. The square signal is generated by loading and unloading a second weight on top of the first one. Since the time constant that best approximates sensor response is 311 seconds, a square wave with a period of 10 seconds can be considered fast. In fact during the 5 seconds of loading only the $1.7 \%$ of the exponential is completed; moreover the exponential evolution of signal is only a part of the entire response that is dominated by the instantaneous term as can be seen from magnitude of parameters (3) and (4); therefore the square wave period is short enough to evaluate only the dynamic sensor response avoiding the other contributions.

The test is repeated with five levels of pressure step amplitude and with two offset values. In total ten test configurations have been used and for each configuration tree repetitions, each lasting 10 minutes, are performed.

The first step of the analysis consists in detecting rising/falling edge of each step using derivative of the signal. The average value within two consecutive edges is calculated and then only the difference $\Delta V$ (Figure 6(a)) between two consecutive steps is considered; in this way effects due to the slow exponential evolution are excluded.

Figures 6(b) and 6(c) present $\Delta V$ as function of the amplitude of the steps. The transfer function found is monotonic 


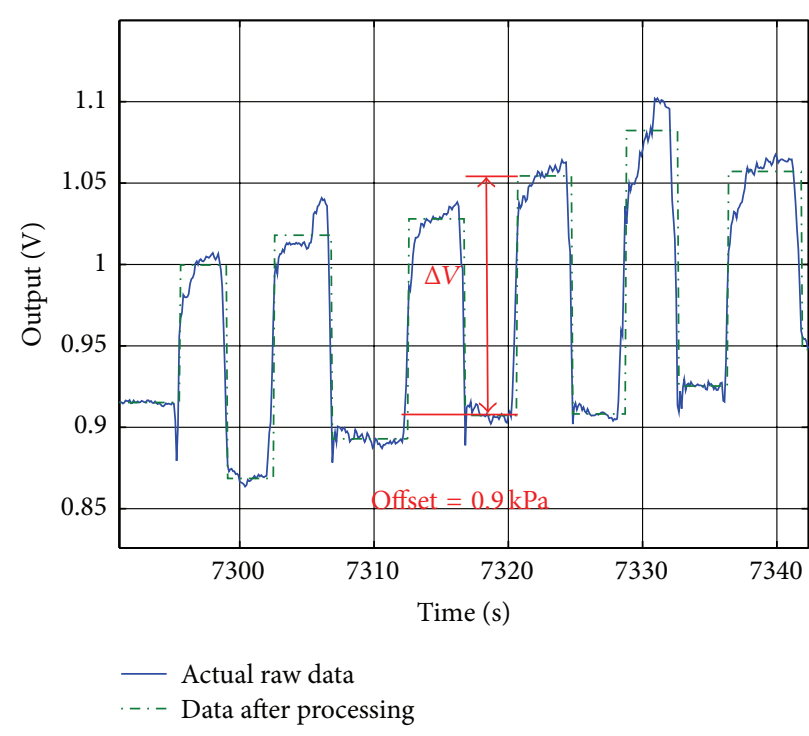

(a)

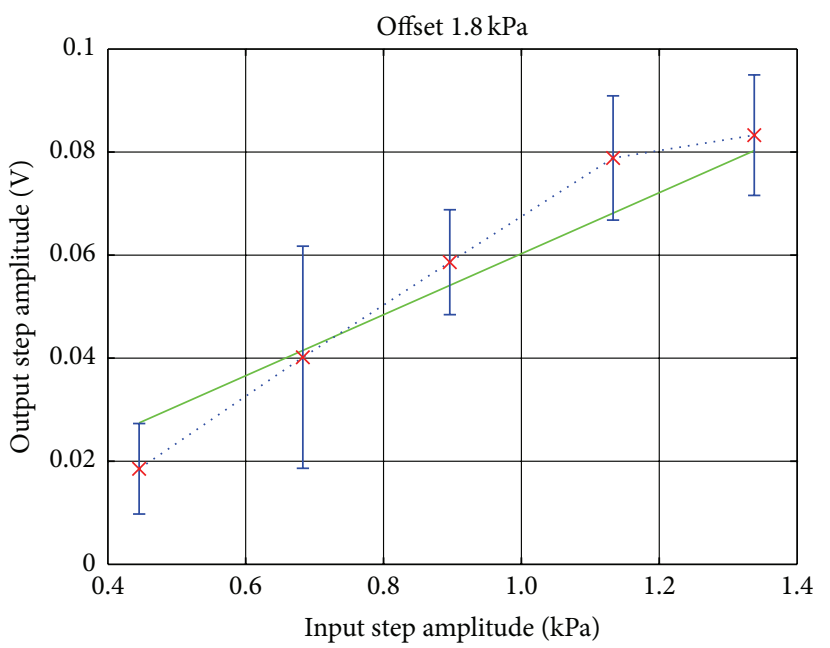

Best fit line

$\times$ Mean values with standard deviation bars

(c)

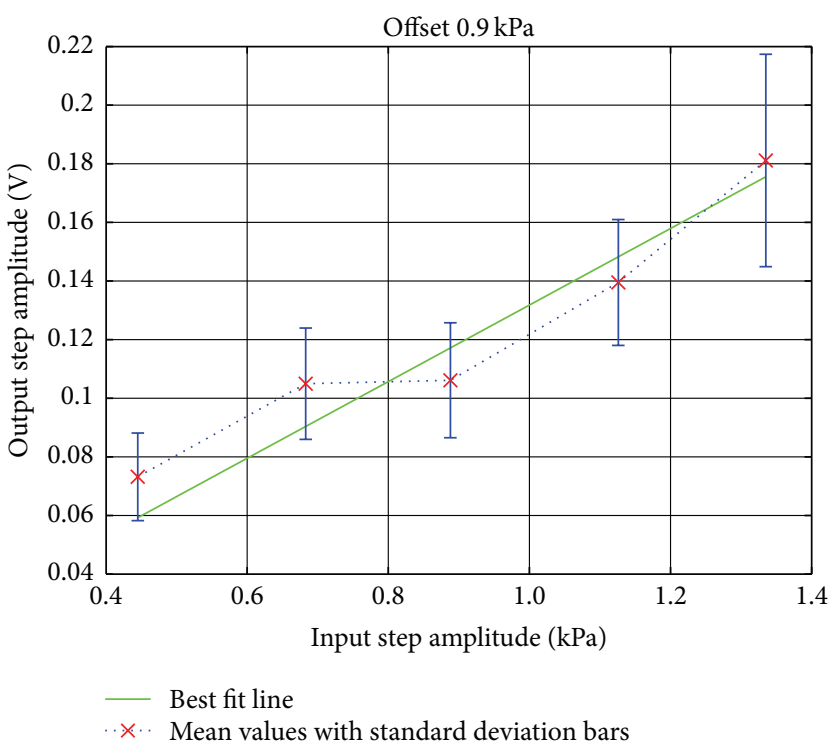

(b)

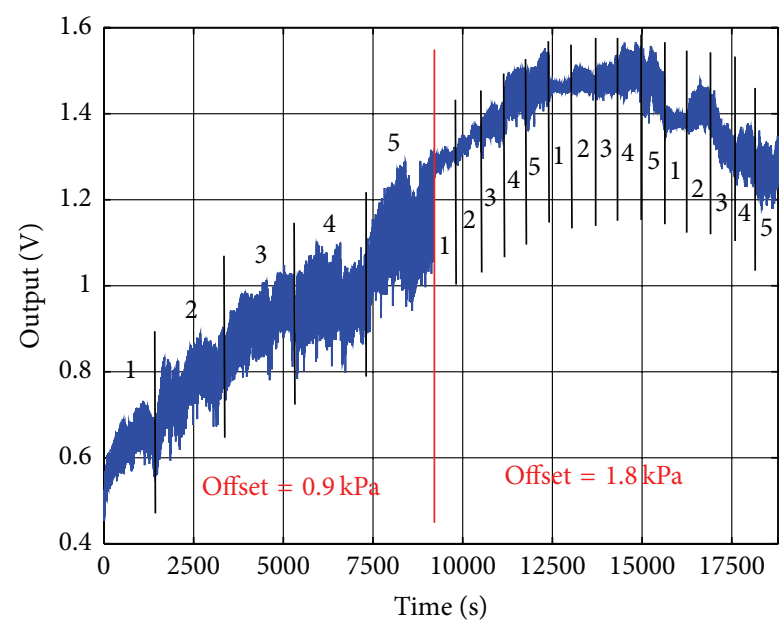

(d)

FIGURE 6: Dynamic signal tests results: (a) zoomed plot of (d), for the analysis only amplitude (in both directions) of the step is considered. Offset refers to offset pressure imposed together with pressure steps. Black numbers mark amplitude of steps; they stay for $1: 0.45 \mathrm{kPa}$ steps; 2: $0.69 \mathrm{kPa}$ steps; 3: $0.89 \mathrm{kPa}$ steps; $4: 1.13 \mathrm{kPa}$ steps; 5: $1.36 \mathrm{kPa}$ steps. (b, c) Observed transfer function (with offset pressure of $0.9 \mathrm{kPa}$ and $1.8 \mathrm{kPa}$ ). Red markers are the mean value of $\Delta V$ together with the standard deviation. (d) All test queued; only raw data plotted.

and, within some intervals, also linear, but standard deviation is up to $53 \%$ of the mean value; therefore, within tested range, only two or three different levels of pressure can be estimated; results are not significantly different when offset is changed. It has to be noted that the processing considers $\Delta V$ between high and low level of each step and therefore the absolute value is discarded. If all tests are queued and plotted (Figure 6(d)), it can be seen that the absolute value is not stable during tests. In fact, in the case with $0.9 \mathrm{kPa}$ offset the absolute value is continuously rising and this can be explained with viscoelastic behavior, but using $1.8 \mathrm{kPa}$ offset firstly it rises and then it falls.
As final comment, sensitivity changes with pressure offset; in particular it decreases. This is consistent with the saturation effect. In particular the angular coefficient (the derivative) of the best fit line is $m=1.3 \times 10^{-4} \mathrm{~V} / \mathrm{Pa}$ for $0.9 \mathrm{kPa}$ offset, and $m=5.9 \times 10^{-4} \mathrm{~V} / \mathrm{Pa}$ for $1.8 \mathrm{kPa}$ offset.

\section{Discussion}

Flexible force sensors have been used for many studies since at least 20 years but their accuracy is controversial. From the test we did on our custom-made sensor we show that the repeatability is one of the major issues. To try solving this we 
TABLE 1: Comparison table for works using Velostat for sensing purposes.

\begin{tabular}{|c|c|c|c|c|c|}
\hline Reference & Year & Matrix/single & $\begin{array}{c}\text { Conditioning } \\
\text { circuit }\end{array}$ & Usage & Resolution \\
\hline This work & 2016 & Single point $(15 \times 30 \mathrm{~mm})$ & $\begin{array}{l}\text { Transimpedance } \\
\text { amplifier }\end{array}$ & $\begin{array}{l}\text { Pressure measurement } \\
\quad(0-2.7 \mathrm{kPa})\end{array}$ & $\begin{array}{c}<450 \mathrm{~Pa} \text { with } \\
\text { precompression of } \\
900 \mathrm{~Pa}\end{array}$ \\
\hline$[44]$ & 2015 & $\begin{array}{c}\text { Matrix } 2 \times 8 \text { sensel }(7 \times 14.5 \mathrm{~cm} \\
\text { each })\end{array}$ & Bias resistor & $\begin{array}{c}\text { Posture recognition, } \\
\text { range } 0-4 \mathrm{~kg}(0-3.9 \mathrm{kPa})\end{array}$ & $\begin{array}{c}<250 \text { gr }(241 \mathrm{~Pa}) \text { with no } \\
\text { precompression }\end{array}$ \\
\hline$[31]$ & 2001 & $\begin{array}{c}\text { Matrix } 8 \times 8 \text { sensel }(5 \times 5 \mathrm{~mm} \\
\text { each })\end{array}$ & Bias resistor & $\begin{array}{c}\text { Pressure measurement } \\
(0-500 \mathrm{kPa})\end{array}$ & $\begin{array}{c}<0.2 \mathrm{~N}(2 \mathrm{kPa}) \text { with no } \\
\text { precompression }\end{array}$ \\
\hline$[39]$ & 2012 & Single point $(15 \times 15 \mathrm{~mm})$ & Bias resistor & $\begin{array}{c}\text { Force measurement } \\
(0-5 \mathrm{~N})\end{array}$ & $\begin{array}{l}0.1 \mathrm{~N}(440 \mathrm{~Pa}) \text { with no } \\
\text { precompression }\end{array}$ \\
\hline$[61]$ & 2015 & Single point $(10 \times 10 \mathrm{~mm})$ & NA & $\begin{array}{c}\text { Pressure measurement } \\
(0-1000 \mathrm{kPa})\end{array}$ & $\begin{array}{c}<1 \mathrm{~kg}(98 \mathrm{kPa}) \text { with no } \\
\text { precompression }\end{array}$ \\
\hline$[62]$ & 2011 & $\begin{array}{c}\text { Matrix } 64 \text { sensel }(10 \times 10 \mathrm{~mm} \\
\text { each })\end{array}$ & NA & $\begin{array}{l}\text { Pressure measurement } \\
\text { map }\end{array}$ & $\begin{array}{c}7 \text { grams }(686 \mathrm{~Pa}) \text { with no } \\
\text { precompression }\end{array}$ \\
\hline$[63]$ & 2014 & $\begin{array}{c}\text { Matrix } 160 \times 160 \mathrm{~cm}(48 \times 48 \\
\text { sensel })\end{array}$ & NA & Gesture recognition & NA \\
\hline$[64]$ & 2011 & Single point & Bias resistor & Event (impact) detection & NA \\
\hline$[65]$ & 2016 & $\begin{array}{c}\text { Matrix } 3 \times 3 \text { sensel }(110 \times 110 \mathrm{~mm} \\
\text { each })\end{array}$ & Bias resistor & Posture analysis & NA \\
\hline$[66]$ & 2014 & Single point $\left(1 \mathrm{~cm}^{2}\right)$ & NA & $\begin{array}{l}\text { Pressure measurement } \\
(0-250 \mathrm{kPa}) \\
\end{array}$ & NA \\
\hline [46] & 2011 & Matrix & Bias resistor & Gesture recognition & $\mathrm{NA}$ \\
\hline$[67]$ & 2015 & Two single point sensors & Bias resistor & $\begin{array}{l}\text { Compressive and } \\
\text { stretching forces }\end{array}$ & NA \\
\hline$[56]$ & 2014 & Matrix $4 \times 4$ sensel & Bias resistor & $\begin{array}{l}\text { Force measurement } \\
\quad(4-60 \mathrm{~N})\end{array}$ & NA \\
\hline
\end{tabular}

applied a technique we called Period Averaging which helps to get more reliable results, but this has some limitations; for example, it can be applied only on signals which are known to have some form of periodicity.

From literature analysis we found that when flexible sensors are used to measure skin interface pressure, results can be affected by inaccuracies due to the nonideality of the tissues that compose the human body $[6,11]$. In fact body softness variation due to bones prominence, sensor bending, and shear forces are effects always present in this kind of measurement that affects sensor's response.

When acquired data is used to classify patterns [41, 43, $58,59]$ (this is mostly done with data coming from sensor matrices instead of a single sensor) the spatial resolution and the number of sensing points are crucial for the measurement; this is confirmed by the fact that sometimes the area of pressure carries more information than pressure magnitude itself [60]. Then this type of sensors should be used in matrices configuration when the area of pressure shape is the parameter to measure or the feature to be classified. Some data on absolute interface pressure can be extracted but it has to be considered only qualitative.

The low accuracy of single point sensors, the cost and complexity of sensor matrices, and issues related to measure body interface pressure are certainly some key factors for the relatively low diffusion of this technology for commercial devices.
We add Table 1 comparing studies based on Velostat for different sensing needs. We provide range and resolution, when available, of some of them, converted in Pascal for an easy comparison with our work. However, some works provide results in terms of percentage of recognition (gesture/postures/etc.) not presenting a characterization of the sensor.

\section{Conclusions}

We performed some tests on a flexible force sensor made with Velostat: the repeatability has been found to be one of the major issues, in particular for long measurement. In fact if random raw data is taken out from result set, up to around $\pm 50 \%$ of error can be found.

A technique called Period Averaging is proposed to limit uncertainty issues but it is not resolutive.

Concluding, we state that measure absolute pressure with this sensing technology could be very challenging, but for other applications where spatial information is the key, they can be used exploiting their low cost and simplicity.

\section{Conflict of Interests}

The authors declare that there is no conflict of interests regarding the publication of this paper. 


\section{Acknowledgment}

This work has been supported by Motorialab s.r.l. [57].

\section{References}

[1] M. Stoppa and A. Chiolerio, "Wearable electronics and smart textiles: a critical review," Sensors, vol. 14, no. 7, pp. 11957-11992, 2014.

[2] K. Grimmer and M. Williams, "Gender-age environmental associates of adolescent low back pain," Applied Ergonomics, vol. 31, no. 4, pp. 343-360, 2000.

[3] S. Crea, M. Donati, S. M. M. De Rossi, C. M. Oddo, and N. Vitiello, "A wireless flexible sensorized insole for gait analysis," Sensors, vol. 14, no. 1, pp. 1073-1093, 2014.

[4] A. M. Howell, T. Kobayashi, H. A. Hayes, K. B. Foreman, and S. J. M. Bamberg, "Kinetic gait analysis using a low-cost insole," IEEE Transactions on Biomedical Engineering, vol. 60, no. 12, pp. 3284-3290, 2013.

[5] S. J. M. Bamberg, A. Y. Benbasat, D. M. Scarborough, D. E. Krebs, and J. A. Paradiso, "Gait analysis using a shoe-integrated wireless sensor system," IEEE Transactions on Information Technology in Biomedicine, vol. 12, no. 4, pp. 413-423, 2008.

[6] D. Giovanelli, N. Giovanelli, P. Taboga et al., "A mechatronic system mounted on insole for analyzing human gait," in Proceedings of the 2nd RSI/ISM International Conference on Robotics and Mechatronics (ICRoM '14), pp. 817-822, Tehran, Iran, October 2014.

[7] S. A. Reid, J. T. Bryant, J. M. Stevenson, and J. B. Doan, "Biomechanical assessment of rucksack shoulder strap attachment location: effect on load distribution to the torso," Tech. Rep. DCIEM-SL-2000-135, Defence and Civil Institute of Environmental Medicine, Toronto, Canada, 2000.

[8] M. Holewijn, "Physiological strain due to load carrying," European Journal of Applied Physiology and Occupational Physiology, vol. 61, no. 3-4, pp. 237-245, 1990.

[9] M. Benocci, L. Rocchi, E. Farella, L. Chiari, and L. Benini, "A wireless system for gait and posture analysis based on pressure insoles and inertial measurement units," in Proceedings of the 3 rd International Conference on Pervasive Computing Technologies for Healthcare (PervasiveHealth '09), pp. 1-6, IEEE, London, UK, April 2009.

[10] H. W. Mackie, J. M. Stevenson, S. A. Reid, and S. J. Legg, "The effect of simulated school load carriage configurations on shoulder strap tension forces and shoulder interface pressure," Applied Ergonomics, vol. 36, no. 2, pp. 199-206, 2005.

[11] P. D. Wettenschwiler, R. Stämpfli, S. Lorenzetti, S. J. Ferguson, R. M. Rossi, and S. Annaheim, "How reliable are pressure measurements with tekscan sensors on the body surface of human subjects wearing load carriage systems?" International Journal of Industrial Ergonomics, vol. 49, pp. 60-67, 2015.

[12] W. Chansirinukor, D. Wilson, K. Grimmer, and B. Dansie, "Effects of backpacks on students: measurement of cervical and shoulder posture," Australian Journal of Physiotherapy, vol. 47, no. 2, pp. 110-116, 2001.

[13] C. Wu, A. Song, Y. Ling, N. Wang, and L. Tian, "A control strategy with tactile perception feedback for emg prosthetic hand," Journal of Sensors, vol. 2015, Article ID 869175, 15 pages, 2015.

[14] R. Koiva, M. Zenker, C. Schurmann, R. Haschke, and H. J. Ritter, "A highly sensitive 3D-shaped tactile sensor," in Proceedings of the IEEE/ASME International Conference on Advanced Intelligent Mechatronics (AIM '13), pp. 1084-1089, IEEE, Wollongong, Australia, July 2013.

[15] T. Zhang, S. Fan, J. Zhao, L. Jiang, and H. Liu, "Multifingered robot hand dynamic grasping control based on fingertip threeaxis tactile sensor feedback," in Proceedings of the 11th World Congress on Intelligent Control and Automation (WCICA '14), pp. 3321-3326, IEEE, Shenyang, China, June 2014.

[16] “Smart socks"” 2015, http://www.sensoriafitness.com/.

[17] "Moticon," 2015, http://www.moticon.de/.

[18] Tekscan, 2015, https://www.tekscan.com/.

[19] Pedar and trublu systems, 2015, http://www.novel.de/.

[20] A. M. Almassri, W. Z. Wan Hasan, S. A. Ahmad et al., "Pressure sensor: state of the art, design, and application for robotic hand," Journal of Sensors, vol. 2015, Article ID 846487, 12 pages, 2015.

[21] M. Y. Chuah, M. Estrada, and S. Kim, "Composite force sensing foot utilizing volumetric displacement of a hyperelastic polymer," in Proceedings of the 25th IEEE/RSJ International Conference on Robotics and Intelligent Systems (IROS '12), pp. 1963-1969, Vilamoura, Portugal, October 2012.

[22] M. Donati, N. Vitiello, S. M. M. De Rossi et al., "A flexible sensor technology for the distributed measurement of interaction pressure," Sensors, vol. 13, no. 1, pp. 1021-1045, 2013.

[23] N. K. Lee, R. S. Goonetilleke, Y. S. Cheung, and G. M. So, "A flexible encapsulated MEMS pressure sensor system for biomechanical applications," Microsystem Technologies, vol. 7, no. 2, pp. 55-62.

[24] K. Hoffmann, Applying the Wheatston Bridge Circuit, HBM Application Note, 1986.

[25] Sensitronics, 2015, http://sensitronics.com/.

[26] L. Viry, A. Levi, M. Totaro et al., "Flexible three-axial force sensor for soft and highly sensitive artificial touch," Advanced Materials, vol. 26, no. 17, pp. 2659-2664, 2014.

[27] Futek, 2015, http://www.futek.com/.

[28] L. Seminara, M. Capurro, P. Cirillo, G. Cannata, and M. Valle, "Electromechanical characterization of piezoelectric PVDF polymer films for tactile sensors in robotics applications," Sensors and Actuators A: Physical, vol. 169, no. 1, pp. 49-58, 2011.

[29] M. Laurenti, D. Perrone, A. Verna, C. Pirri, and A. Chiolerio, "Development of a flexible lead-free piezoelectric transducer for health monitoring in the space environment," Micromachines, vol. 6, no. 12, pp. 1729-1744, 2015.

[30] K. F. De Jesus, M. H. Cheng, L. Jiang, and E. G. Bakhoum, "Resolution enhancement method used for force sensing resistor array," Journal of Sensors, vol. 2015, Article ID 647427, 12 pages, 2015.

[31] Z. Del Prete, L. Monteleone, and R. Steindler, "A novel pressure array sensor based on contact resistance variation: metrological properties," Review of Scientific Instruments, vol. 72, no. 2, pp. 1548-1553, 2001.

[32] S. Stassi, V. Cauda, G. Canavese, and C. F. Pirri, "Flexible tactile sensing based on piezoresistive composites: a review," Sensors, vol. 14, no. 3, pp. 5296-5332, 2014.

[33] M. Castellino, A. Chiolerio, M. I. Shahzad, P. V. Jagdale, and A. Tagliaferro, "Electrical conductivity phenomena in an epoxy resin-carbon-based materials composite," Composites Part A: Applied Science and Manufacturing, vol. 61, pp. 108-114, 2014.

[34] L. Wang, J. Li, and Y. Han, "A prototype of piezoresistive fringeelectrodes-element based on conductive polymer composite," IEEE Transactions on Electron Devices, vol. 61, no. 1, pp. 129-135, 2014. 
[35] M. Melnykowycz, B. Koll, D. Scharf, and F. Clemens, "Comparison of piezoresistive monofilament polymer sensors," Sensors, vol. 14, no. 1, pp. 1278-1294, 2014.

[36] M. Knite, V. Teteris, A. Kiploka, and J. Kaupuzs, "Polyisoprenecarbon black nanocomposites as tensile strain and pressure sensor materials," Sensors and Actuators A: Physical, vol. 110, no. 1-3, pp. 142-149, 2004.

[37] K. Weiss and H. Worn, "The working principle of resistive tactile sensor cells," in Proceedings of the IEEE International Conference on Mechatronics and Automation (ICMA '05), vol. 1, pp. 471476, Niagara Falls, Canada, July-August 2005.

[38] M.-A. Lacasse, V. Duchaine, and C. Gosselin, "Characterization of the electrical resistance of carbon-black-filled silicone: application to a flexible and stretchable robot skin," in Proceedings of the IEEE International Conference on Robotics and Automation (ICRA '10), pp. 4842-4848, IEEE, Anchorage, Alaska, USA, May 2010.

[39] M. Kalantari, J. Dargahi, J. Kövecses, M. G. Mardasi, and S. Nouri, "A new approach for modeling piezoresistive force sensors based on semiconductive polymer composites," IEEE/ ASME Transactions on Mechatronics, vol. 17, no. 3, pp. 572-581, 2012.

[40] L. Wang, Y. Han, C. Wu, and Y. Huang, "A solution to reduce the time dependence of the output resistance of a viscoelastic and piezoresistive element," Smart Materials and Structures, vol. 22, no. 7, Article ID 075021, 2013.

[41] W. Xu, M.-C. Huang, N. Amini, L. He, and M. Sarrafzadeh, "eCushion: a textile pressure sensor array design and calibration for sitting posture analysis," IEEE Sensors Journal, vol. 13, no. 10, pp. 3926-3934, 2013.

[42] S. Khan, S. Tinku, L. Lorenzelli, and R. S. Dahiya, "Flexible tactile sensors using screen-printed $\mathrm{P}(\mathrm{VDF}-\mathrm{TrFE})$ and MWCNT/ PDMS composites," IEEE Sensors Journal, vol. 15, no. 6, pp. 3146-3155, 2015.

[43] M. Lombardi, A. Pieracci, P. Santinelli, R. Vezzani, and R. Cucchiara, "Sensing floors for privacy-compliant surveillance of wide areas," in Proceedings of the 10th IEEE International Conference on Advanced Video and Signal Based Surveillance (AVSS '13), pp. 105-110, IEEE, Kraków, Poland, August 2013.

[44] R. Barba, Á. P. de Madrid, and J. G. Boticario, "Development of an inexpensive sensor network for recognition of sitting posture," International Journal of Distributed Sensor Networks, vol. 2015, Article ID 969237, 13 pages, 2015.

[45] Y.-T. Lai, Y.-M. Chen, and Y.-J. J. Yang, "A novel CNTPDMS-based tactile sensing array with resistivity retaining and recovering by using dielectrophoresis effect," Journal of Microelectromechanical Systems, vol. 21, no. 1, pp. 217-223, 2012.

[46] E. Jeong, J. Lee, and D. Kim, "Finger-gesture recognition glove using velostat (ICCAS 2011)," in Proceedings of the 11th International Conference on Control, Automation and Systems (ICCAS '11), pp. 206-210, IEEE, Gyeonggi-Do, South Korea, October 2011.

[47] C. Lebosse, P. Renaud, B. Bayle, and M. de Mathelin, "Modeling and evaluation of low-cost force sensors," IEEE Transactions on Robotics, vol. 27, no. 4, pp. 815-822, 2011.

[48] A. Hollinger and M. M. Wanderley, "Evaluation of commercial forcesensing resistors," in Proceedings of the International Conference on New Interfaces for Musical Expression, 2006.

[49] A. W. P. Buis and P. Convery, "Calibration problems encountered while monitoring stump/socket interface pressures with force sensing resistors: techniques adopted to minimise inaccuracies," Prosthetics and Orthotics International, vol. 21, no. 3, pp. 179-182, 1997.

[50] J. Florez and A. Velasquez, "Calibration of force sensing resistors (fsr) for static and dynamic applications," in Proceedings of the IEEE ANDESCON Conference, pp. 1-6, Bogota, Colombia, September 2010.

[51] R. S. Hall, G. T. Desmoulin, and T. E. Milner, "A technique for conditioning and calibrating force-sensing resistors for repeatable and reliable measurement of compressive force," Journal of Biomechanics, vol. 41, no. 16, pp. 3492-3495, 2008.

[52] X.-W. Zhang, Y. Pan, Q. Zheng, and X.-S. Yi, “Time dependence of piezoresistance for the conductor-filled polymer composites," Journal of Polymer Science Part B: Polymer Physics, vol. 38, no. 21, pp. 2739-2749, 2000.

[53] K. Oppermann, B. R. Arminger, and B. G. Zagar, "Smart hysteresis compensation of a magneto-elastic force sensor based on Terfenol-D," in Proceedings of the IEEE International Instrumentation and Measurement Technology Conference (I2MTC '10), pp. 662-667, IEEE, Austin, Tex, USA, May 2010.

[54] R. Bonnaire, M. Verhaeghe, J. Molimard, P. Calmels, and R. Convert, "Characterization of a pressure measuring system for the evaluation of medical devices," Proceedings of the Institution of Mechanical Engineers, Part H: Journal of Engineering in Medicine, vol. 228, no. 12, pp. 1264-1274, 2014.

[55] E. R. Komi, J. R. Roberts, and S. J. Rothberg, "Evaluation of thin, flexible sensors for time-resolved grip force measurement," Proceedings of the Institution of Mechanical Engineers, Part C: Journal of Mechanical Engineering Science, vol. 221, no. 12, pp. 1687-1699, 2007.

[56] L. G. Harris, Design and fabrication of a piezoresistive tactile sensor for ergonomic analyses [Ph.D. thesis], The University of Guelph, 2014.

[57] Cit technology, 2016, http://cittechnology.com/, https://web .archive.org/.

[58] M.-C. Huang, J. J. Liu, W. Xu, N. Alshurafa, X. Zhang, and M. Sarrafzadeh, "Using pressure map sequences for recognition of on bed rehabilitation exercises," IEEE Journal of Biomedical and Health Informatics, vol. 18, no. 2, pp. 411-418, 2014.

[59] M. Benocci, E. Farella, and L. Benini, "A context-aware smart seat," in Proceedings of the 4th IEEE International Workshop on Advances in Sensors and Interfaces (IWASI '11), pp. 104-109, IEEE, Savelletri di Fasano, Italy, June 2011.

[60] L. F. M. Kuijt-Evers, T. Bosch, M. A. Huysmans, M. P. de Looze, and P. Vink, "Association between objective and subjective measurements of comfort and discomfort in hand tools," Applied Ergonomics, vol. 38, no. 5, pp. 643-654, 2007.

[61] X. Lin and B.-C. Seet, "A linear wide-range textile pressure sensor integrally embedded in regular fabric," IEEE Sensors Journal, vol. 15, no. 10, pp. 5384-5385, 2015.

[62] R. van Donselaar and W. Chen, "Design of a smart textile mat to study pressure distribution on multiple foam material configurations," in Proceedings of the 4th International Symposium on Applied Sciences in Biomedical and Communication Technologies (ISABEL '11), p. 129, ACM, Barcelona, Spain, October 2011.

[63] M. Carrozzino, G. Avveduto, F. Tecchia, P. Gurevich, and B. Cohen, "Navigating immersive virtual environments through a foot controller," in Proceedings of the 20th ACM Symposium on Virtual Reality Software and Technology (VRST '14), pp. 23-26, Edinburgh, UK, November 2014.

[64] E. Fairman, The smart vest [Ph.D. thesis], Worcester Polytechnic Institute, 2011. 
[65] B. W. Lee and H. Shin, "Feasibility study of sitting posture monitoring based on piezoresistive conductive film-based flexible force sensor," IEEE Sensors Journal, vol. 16, no. 1, pp. 15-16, 2016.

[66] J. H. Low, K. P. May, and C. H. Yeow, "Redistribution of plantar pressure with pneumatic insole," in Proceedings of the International Convention on Rehabilitation Engineering \& Assistive Technology (i-CREATe '14), Singapore Therapeutic, Assistive \& Rehabilitative Technologies (START) Centre, Singapore, 2014.

[67] M. Vega-Barbas, I. Pau, J. Ferreira, E. Lebis, and F. Seoane, "Utilizing smart textiles-enabled sensorized toy and playful interactions for assessment of psychomotor development on children," Journal of Sensors, vol. 2015, Article ID 898047, 9 pages, 2015. 


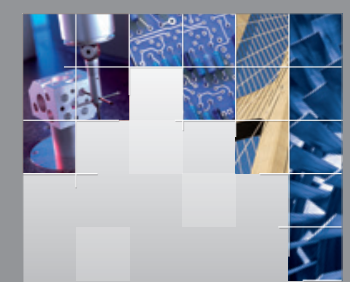

\section{Enfincering}
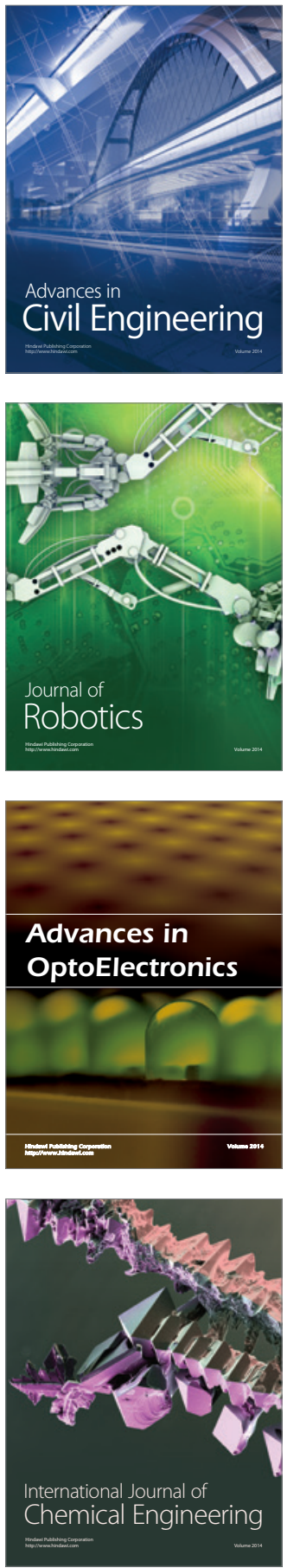

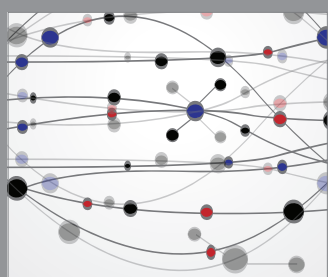

The Scientific World Journal

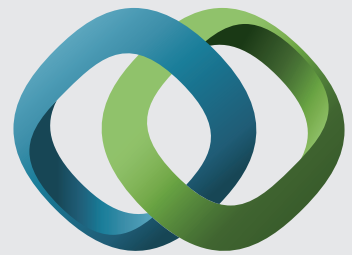

\section{Hindawi}

Submit your manuscripts at

http://www.hindawi.com
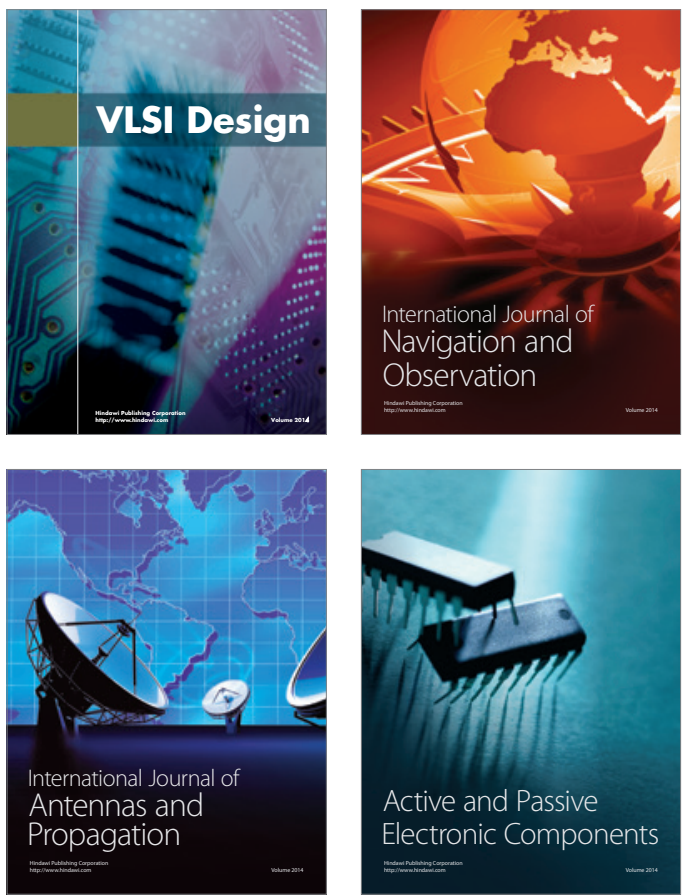
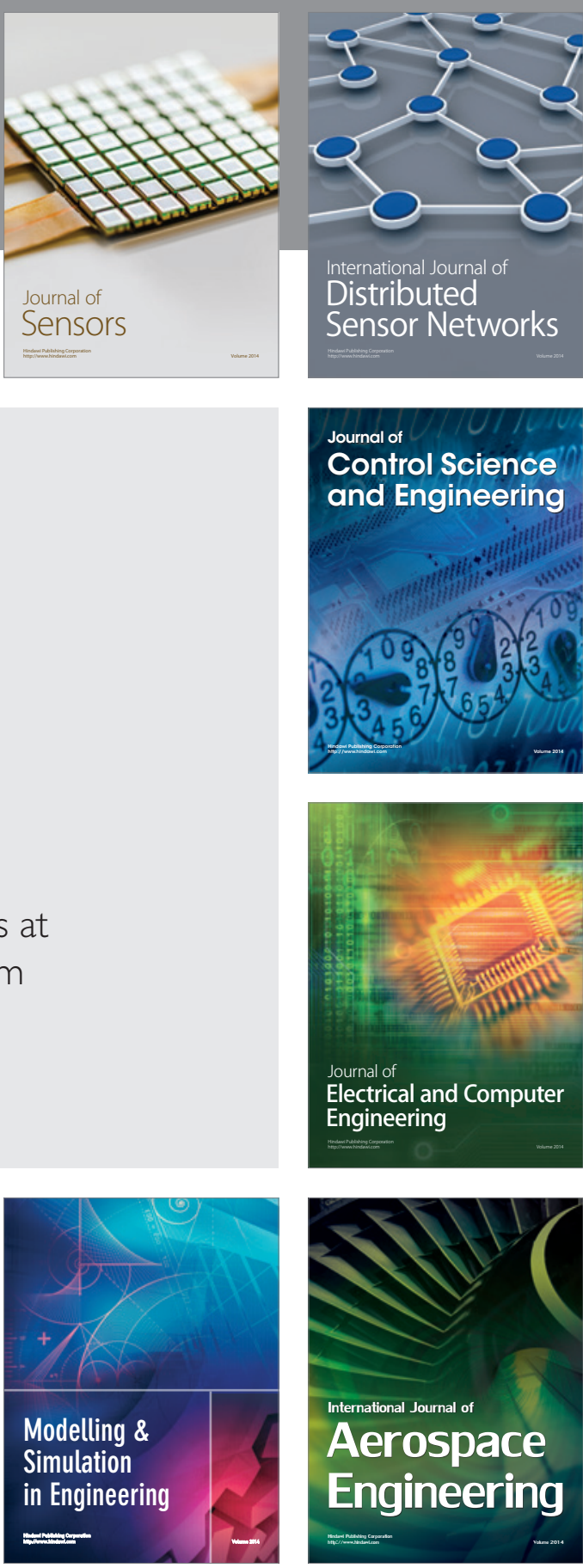

International Journal of

Distributed

Sensor Networks

Journal of

Control Science

and Engineering
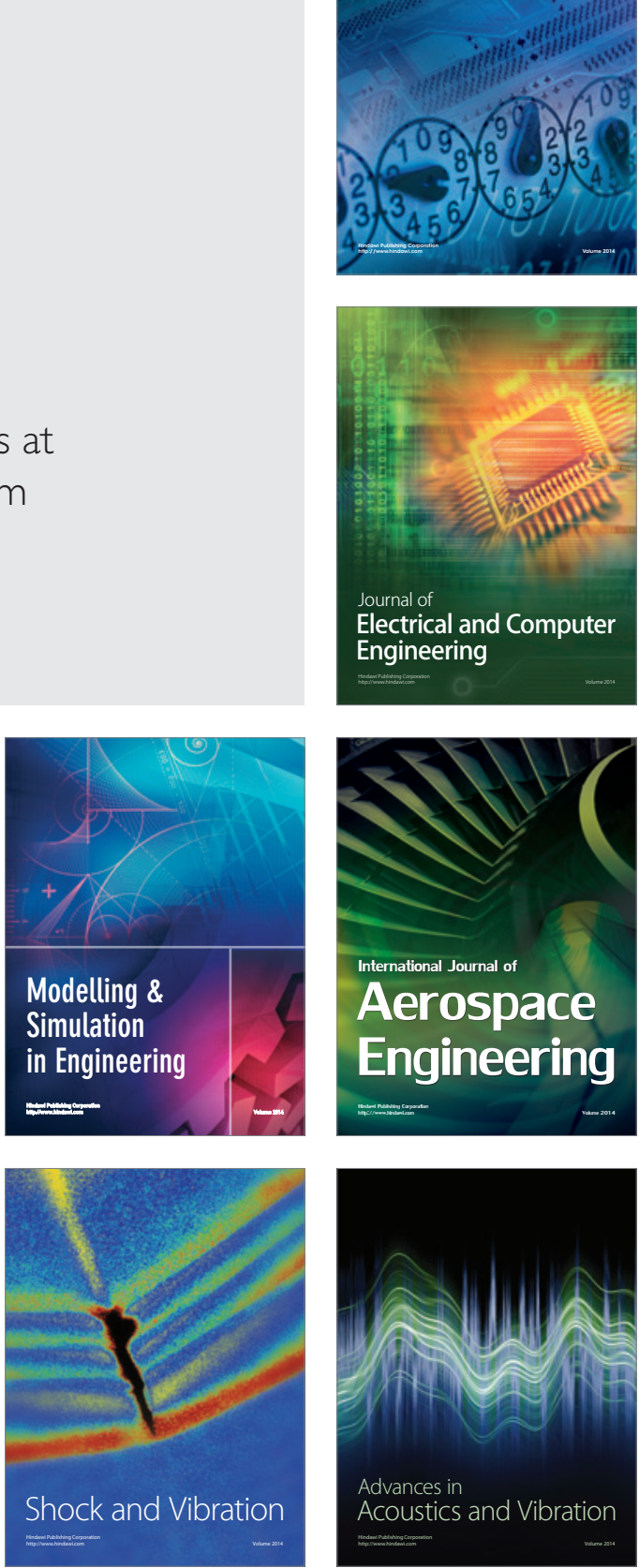